\title{
Stability of evoked potentials during auditory attention
}

\author{
LYNN C. OATMAN \\ United States Army Human Engineering Laboratory, Aberdeen Proving Ground, Maryland
}

\begin{abstract}
Click-evoked potentials were recorded from the round window (cochlear microphonic and auditory nerve), cochlear nucleus, and auditory cortex of unanesthetized cats during periods of auditory attention and nonattention. The clicks (irrelevant stimuli) of increasing intensity were presented continuously as background before, during, and after the presentation of a warning stimulus (S1) followed by an imperative (relevant) stimulus (S2) to which the cats made a behavioral response. At all electrode sites, when the cats were attentive to S2, the mean amplitudes of background irrelevant click-evoked potentials within the S1-S2 interval were not significantly different from those of the pretest and posttest control sessions. During auditory attention, no evidence was obtained for peripheral gating at the auditory nerve by the olivocochlear bundle. The dissociation observed between the amplitudes of background irrelevant click-evoked potentials and behavioral performance may reflect overlearning of the S1-S2 response task.
\end{abstract}

During selective attention, a selective process occurs within the central nervous system (CNS) in that relevant sensory stimuli are perceived while irrelevant stimuli are rejected (Hernández-Peón, 1966). A central issue in the related literature has been whether the neural mechanism that allows an organism to process sensory information selectively occurs at an "early" or "late" stage of processing, or at both (Hillyard \& Kutas, 1983). Since the behavioral evidence has not been able to resolve this issue in favor of either early-selection (Broadbent, 1958; Treisman, 1969) or late-selection (Deutsch \& Deutsch, 1963; Norman, 1968) models, several researchers have sought to determine whether brain evoked potentials (EPs) and other event-related potentials (ERPs) can be used to index the various stages of information processing (e.g., Näätänen, 1982).

A number of studies that used ERPs to examine the neural mechanisms of selective attention in humans have had contradictory results. Research supporting the earlyselection hypothesis in the auditory modality has shown significant increases in evoked-potential amplitude of the N1 component when a subject attended to a relevant stimulus, compared with when his/her attention was directed to other (irrelevant) stimuli in the same modality (Hillyard, Hink, Schwent, \& Picton, 1973; Hink \& Hillyard, 1976; Schwent \& Hillyard, 1975; Schwent, Hillyard, \& Galambos, 1976a, 1976b; Schwent, Snyder, \& Hillyard,

\footnotetext{
In conducting the present research, the investigator adhered to the Guide for Laboratory Animal Facilities for Laboratory Animal Resources, National Academy of Sciences, National Research Council, Washington, DC. This paper is part of the public domain and may be reproduced in full or in part for any purpose of the United States Government. The author gratefully acknowledges the assistance of Joel T. Kalb in computer-graphics programming and Donna M. Kramer in reducing the data. The author's mailing address is U.S. Army Human Engineering Laboratory, Aberdeen Proving Ground, MD 21005-5001.
}

1976). Conversely, when attention was directed toward a stimulus in another modality, Lukas $(1980,1981)$ found that several early brainstem auditory evoked potentials were diminished, although Picton, Stapells, and Campbell (1981) failed to replicate this effect. In subsequent studies, Hansen and Hillyard $(1980,1983)$ examined "difference waveforms" and observed a prolonged negative ERP (termed processing negativity or $N d$ wave). Since this enhanced negativity has a short latency of onset $(60-80 \mathrm{msec})$, it was taken to be an index of an earlyselection process, which allows irrelevant stimuli to be rejected quickly and efficiently (Hansen \& Hillyard, 1984).

Additional support for an early-selection process has been suggested by other researchers who have observed attention-related differences between the ERP components of attended and unattended stimuli in the visual modality (Hillyard \& Münte, 1984; Mangun, Hansen, \& Hillyard, 1986) and in the somatosensory modality (Desmedt \& Robertson, 1977; Lavine, Buchsbaum, \& Schechter, 1980). Eason, Oakley, and Flowers (1983) and Eason (1984), in work with the visual modality, found that amplitudes of the b-wave and after-potential of the electroretinogram (ERG) were larger to attended than to unattended visual stimuli, and they interpreted these results as providing further evidence for early sensory filtering of irrelevant, unattended information. However, Mangun et al.(1986) tried to replicate the ERG finding and found no attention effect on the b-wave or the after-potential of the ERG. Although these studies generally lend credibility to the early-selection hypothesis, other studies have found no attention-related changes of the subcortical components in the auditory modality (Picton \& Hillyard, 1974; Picton, Hillyard, Galambos, \& Schiff, 1971; Picton et al., 1981), the visual modality (Wastell \& Kleinman, 1980), or the somatosensory modality (Velasco \& Velasco, 1975; Velasco, Velasco, \& Olvera, 1980). 
Hernández-Peón (1966) proposed a possible physiological mechanism for early selection. He suggested that changes in evoked-potential amplitude due to attention reflect a peripheral modulating mechanism that selectively enhances sensory inputs to relevant stimuli or inhibits sensory inputs to irrelevant stimuli or both. These early experiments (Hernández-Peón, 1966; Hernández-Peón, Scherrer, \& Jouvet, 1956), which demonstrated a reduction in amplitude of cochlear nucleus evoked potentials to clicks when cats were attentive to visual or olfactory stimuli, have been criticized on methodological grounds (Worden, 1966). However, in later studies that controlled for stimulus constancy and the effects of middle-ear muscles, Oatman $(1971,1976)$ provided evidence that auditory evoked potentials at the receptor and the cortical levels are suppressed in amplitude while an animal is attending to visual stimulation. Oatman (1982) suggested that while an animal is paying attention to visual stimulation, a central inhibitory mechanism suppresses irrelevant auditory stimuli through the action of the olivocochlear bundle (OCB). The existence of the OCB (Rasmussen, 1960 ), which projects to the hair cells of the cochlea, has been shown to inhibit auditory input at the receptor level during habituation and distraction experiments (Bũno, Velluti, Handler, \& Garcia-Austt, 1966) and during attention to a visual stimulus (Oatman, 1971, 1976; Oatman \& Anderson, 1977). This evidence supports the idea that the OCB performs an inhibitory function by controlling auditory input to the CNS at the peripheral level, a process that may constitute a neural mechanism for early selection. Although the previous studies (Oatman, 1971, 1976; Oatman \& Anderson, 1977) demonstrated a crossmodality gating effect during selective attention, the question remains as to whether a similar gating function might be evident within the auditory modality during attention to auditory stimuli.

The purpose of the present experiment was to determine whether attention to relevant auditory stimuli (two tones presented successively) enhances or inhibits irrelevant auditory click-evoked potentials presented to the same ear. The experimental paradigm was that of a variableforeperiod reaction-time experiment, which is typically used in the development of the contingent negative variation (CNV; Tecce, 1972; Walter, Cooper, Aldridge, McCallum, \& Winter, 1964). A warning or preparatory stimulus (S1) was followed by an imperative stimulus (S2), to which the subject made a behavioral response and received food reinforcement for a correct response. To increase the subjects' attentiveness and avoid temporal conditioning, the S1-S2 interval was varied randomly between 1 and $6 \mathrm{sec}$. In the usual paradigm, the S1-S2 interval is empty or silent while the subject maintains a single attention set in order to make a response to $\mathbf{S 2}$ (Tecce, 1972). In the present experiment, however, irrelevant click stimuli were presented within the S1-S2 interval so that I could examine the changes in click-evoked potentials associated with attentive and nonattentive states of the animal. I thought that if selective attention within the auditory modality initiated a gating or filtering effect similar to the cross-modality effect (Oatman, 1971, 1976), then the irrelevant click-evoked potentials would be suppressed in amplitude through the action of the $\mathrm{OCB}$ at the receptor level in the afferent auditory pathway.

On the other hand, there have been many reports of the enhancement of single- and multiple-unit responses to a positive auditory conditioned stimulus during classical and instrumental conditioning. These enhanced auditory responses have been observed in the cochlear nucleus during classical conditioning in the cat (Oleson, Ashe, \& Weinberger, 1975); the inferior colliculus during appetitive conditioning in the rat (Birt \& Olds, 1981, 1982); medial geniculate body during classical conditioning in the cat (Ryugo \& Weinberger, 1978), appetitive conditioning in the rat (Disterhoft \& Olds, 1972), and avoidance conditioning in the rabbit (Gabriel, Miller, \& Saltwick, 1976; Gabriel, Orona, Foster, \& Lambert, 1982; Gabriel, Saltwick, \& Miller, 1975); and auditory cortex during classical conditioning in the cat (Diamond \& Weinberger, 1984; Weinberger, Hopkins, \& Diamond, 1984), avoidance conditioning in the rabbit (Gabriel et al., 1982), and instrumental conditioning in the monkey (Benson \& Hienz, 1978; Goldstein, Benson, \& Hienz, 1982). In addition, Hansen and Hillyard (1983) reported that even though subjects responded only to the relevant stimuli belonging to the attended channel, all the auditory stimuli in that channel-relevant and irrelevant alike-elicited ERPs with similarly enhanced $\mathrm{N} 1$ amplitudes. In the present study, the possibility existed that receptor enhancement of irrelevant click-evoked potentials within the S1-S2 interval could occur during attention to the relevant auditory stimulus (S2). Amplitude measures of the auditory evoked potentials recorded concurrently at the receptor and the cortical levels were used to assess the effects of auditory attention on irrelevant auditory click stimuli.

The study was also designed to determine the relationship between the intensity of the irrelevant click stimuli and the amount of the evoked-potential enhancement or suppression under conditions of attention and nonattention within the auditory modality. Stimulus intensity has been suggested to be an important variable in determining the magnitude of the N1 effect (Schwent, Hillyard, \& Galambos, 1976a, 1976b) and in accounting for the failure of several studies to obtain reliable attention effects upon N1 components of the evoked potential (Schwent, Hillyard, \& Galambos, 1976b). These studies have shown that the magnitude of the $\mathrm{N} 1$ enhancement was more pronounced when low-intensity stimuli were used than when high-intensity stimuli were used. Oatman (1976) also suggested that the intensity of the irrelevant stimuli was important in determining the amount of crossmodality suppression of the auditory evoked potentials. His results showed that during attention to visual stimuli, greater suppression of irrelevant click-evoked potentials occurred at low-intensity clicks than at high-intensity clicks. In the present study, a wide range of click intensi- 
ties was presented under conditions of attention and nonattention, because the enhancement or inhibition of irrelevant click-evoked potentials might be expected to emerge most clearly to low-intensity clicks.

\section{METHOD}

\section{Subjects}

Four female cats, each weighing approximately $2.5 \mathrm{~kg}$, had electrodes placed on the round window and bilaterally in the cochlear nucleus and auditory cortex under sodium pentobarbital anesthesia $(0.5 \mathrm{ml} / \mathrm{kg}$ at a concentration of $65 \mathrm{mg} / \mathrm{ml})$. The cochlear nucleus electrodes were stereotaxically implanted through small holes bored in the skull according to coordinates in the stereotaxic atlas of Snider and Niemer (1961). The concentric bipolar electrodes were made of $0.2-\mathrm{mm}$ stainless steel wire and inserted into $0.5-\mathrm{mm}$ stainless steel tubing (Rhodes Model NEX-100). Both the wire and the tubing were coated with an Epoxylite insulator up to $0.5 \mathrm{~mm}$ from the tip; the tips were $1.0 \mathrm{~mm}$ apart. The cortical electrodes were flattened monopolar silver-ball electrodes stereotaxically implanted on the dura over the primary auditory cortex (AI). The round window electrode was a 0.2-mm ball-tipped stainless steel wire in polyethylene tubing. At the time of the round window implantation, the tendons of the stapedius and tensor tympani middle-ear muscles were cut. The indifferent electrode was a stainless steel screw placed over the frontal sinus; another stainless steel screw, placed at the posterior part of the skull, was used as an internal ground for the animal. A detailed explanation of the surgical preparation used in this experiment can be found elsewhere (Oatman, 1971, 1976).

\section{Histology}

At the end of the experiment, the cats were given a lethal overdose of intravenous sodium pentobarbital. Electrolytic lesions were produced at the recording sites of each concentric electrode. The lesion current was $1 \mathrm{~mA}$ for $15 \mathrm{sec}$. The brains were removed and placed in formalin and potassium ferrocyanide. All placements were verified histologically using unstained, frozen sections (Siegel, 1968). For all 4 cats, the histology slides confirmed that the electrodes were placed in the dorsal cochlear nucleus. Examination of the brains confirmed that the auditory electrodes were placed on the middle ectosylvian gyrus (AI). Middle ears were examined with a Bausch and Lomb Stereozoom Seven dissecting microscope to determine that the middle-ear muscle tendons had been completely severed.

\section{Acoustic Stimulation}

The relevant auditory stimuli consisted of pairs of tones presented successively. The first tone (S1) of the pair, which served as a warning stimulus for the arrival of the second (imperative) tone (S2), was a $1000-\mathrm{Hz}$ tone (2.5-msec rise-decay time, $0.5-\mathrm{sec}$ duration). The second tone of the pair, the imperative stimulus, was an 800 $\mathrm{Hz}$ tone (2.5-msec rise-decay time, 4 -sec duration). The cat had to respond to $S 2$ by pushing the response key to receive food reward. The response key, operated by the cat, terminated $\mathbf{S 2}$. To perform the task, the cats had to inhibit their response to SI, wait for the onset of $S 2$, and push the response key to receive food reinforcement; however, the cats did not know precisely when $S 2$ would begin, because its onset was delayed randomly between 1 and $6 \mathrm{sec}$. With the variable delay of the onset of $\$ 2$, attention was maintained and temporal conditioning between $S 1$ and $S 2$ avoided. If the cat responded during the S1-S2 interval (T1, Figure 1), it received no reinforcement and the onset of the next trial was delayed $25 \mathrm{sec}$. A trial consisted of one $S 1-S 2$ response sequence, and the time between trials varied from 20 to $45 \mathrm{sec}$. Both tones, $S 1$ and S2, were generated by two wide-range oscillators (Hewlett-Packard Model
200CDR) and monitored by two electronic counters (Computer Measurement Corporation Model 608). The tones were presented at $85 \mathrm{~dB} \mathrm{SPL}$ (re $0.0002 \mu \mathrm{bar}$ ) through a sound-tube system that terminated at the entrance to the cat's external meatus. The sound tube was not fastened to the pinna, but was held firmly in place at its entrance by a bracket attached to the electrode plug. Sound pressures were calibrated with a $0.635-\mathrm{cm}$ condenser microphone (Brüel and Kjaer Type 4135) and placed perpendicularly to, and just in front of the end of, the sound tube. Movements of the sound tube to different positions within the test cubicle did not change the output voltage from the microphone.

The irrelevant stimuli consisted of auditory clicks superimposed within the interstimulus (S1-S2) interval. Auditory clicks were presented continuously at a rate of one per second as background before, during, and after the presentation of the S1-S2 response paradigm, but they were not synchronized with the onset of the relevant tones. The auditory clicks were generated by a $90-\mu \mathrm{sec}$ squarewave pulse (Tektronix 26G3). The pulses were led through a highpass filter (Allison Laboratories Model 2-B, $4800 \mathrm{~Hz}$ ), and through a decade attenuator (General Radio Model GR-1450) and a power amplifier (Crown Model D-150A) to a driver (University Model ID-60). The clicks were presented at a rate of one per second at each 10-dB intensity step from 35 to $125 \mathrm{~dB}$ SPL (re $.0002 \mu \mathrm{bar}$ ) through the sound-tube system that terminated at the entrance to the cat's external meatus. The relevant auditory stimuli (S1 and S2) and the simultaneous irrelevant clicks were presented to the same ear.

\section{Data Collection and Procedure}

The tests were conducted in a sound-attenuating box that had a response key and a liquid food dipper mounted in the floor, and a driver, with a sound tube attached, mounted in the top of the box.

Four weeks after surgery, the cats were placed into the soundattenuating test cubicle and trained on the S1-S2 response paradigm using food reinforcement. They were gradually deprived of food until they were on a 22-h deprivation schedule. Then they learned the S1-S2 response task, with Purina tuna mixed with water as food reinforcement. All cats received either 100 trials or 50 food reinforcements on each day of training, until they reached a criterion of 20 consecutive correct responses. After testing, the cats were given free access to Purina Cat Chow for $1 \mathrm{~h}$. The cats were maintained under a 12:12-h light:dark cycle in which the lights were turned on at $0600 \mathrm{~h}$ and turned off at $1800 \mathrm{~h}$. The cats were tested every morning in the same sequence, beginning at $0800 \mathrm{~h}$.

After the cats were trained to perform at criterion, the electrodes were checked and the data were collected in recording sessions that consisted of three different periods: (1) a pretest control period during which the cat was awake, relaxed, and receiving only click stimuli; (2) an experimental period during which the cat was receiving simultaneously irrelevant auditory clicks and relevant tones (S1-S2 response) with food reinforcement for a correct response; and (3) a posttest control period similar to the pretest control period. Figure 1 shows a schematic diagram of the stimulus presentation for the three recording periods. The data collection for the experimental period began $0.5 \mathrm{sec}$ after the ending of the $1000-\mathrm{Hz}$ tone (S1) to prevent masking of the evoked potentials, and included only those evoked potentials presented during $T 1$, that is, those within the S1-S2 interval (Figure 1). The three recording sessionspretest control, experimental, and posttest control-were conducted during the same day. Evoked potentials to clicks for each of the three recording sessions were then collected at each of 10 different intensities ( 1 intensity per day) in an ascending order of presentation from 35 to $125 \mathrm{~dB}$ SPL (re $0.0002 \mu$ bar).

Simultaneous recordings to click stimuli were obtained from the round window (cochlear microphonic and auditory nerve), the cochlear nucleus, and the auditory cortex. Recordings were obtained from unrestrained animals via a Microdot shielded cable connected 
PRETEST CONTROL

$1000 \mathrm{HZ}$ TONE OFF

$800 \mathrm{HZ}$ TONE OFF

AUDITORY CLICKS

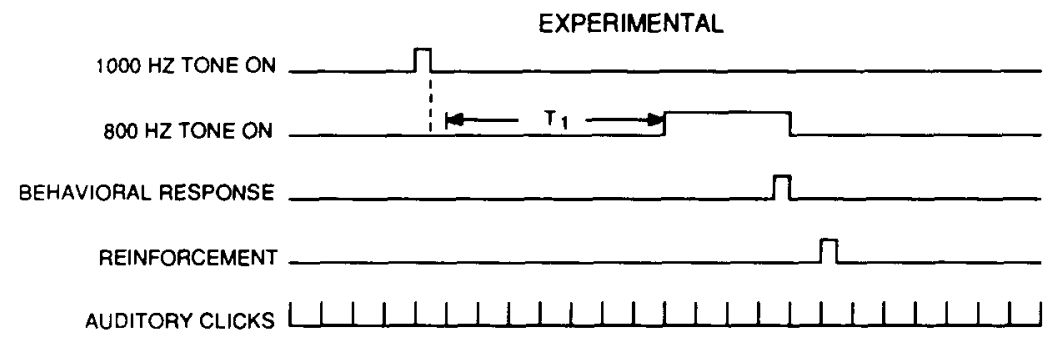

POSTTEST CONTROL

$1000 \mathrm{HZ}$ TONE OFF

$800 \mathrm{HZ}$ TONE OFF

AUDITORY CLICKS

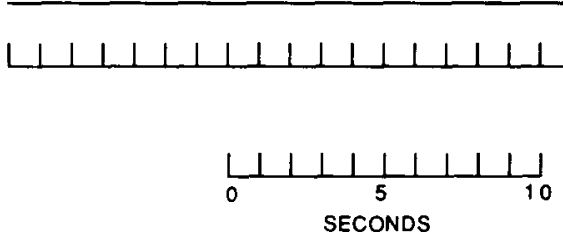

Figure 1. Schematic diagram of the stimulus presentation of the auditory tones and clicks for experimental and control recording sessions.

to an electroencephalograph (Grass Model 7), placed outside the sound-attenuating cubicle. At the same time, the click-evoked potentials were recorded on a 14-channel FM tape recorder (Sangamo Model 4700), from which they were led into a signal averager (Nicolet Med Model 80) and written on an $x-y$ plotter (HewlettPackard Model 7035B). Figure 2 shows an example of the clickevoked responses from the round window, cochlear nucleus, and auditory cortex and indicates how the peak-to-peak measurement was made for each electrode placement. Peak-to-peak amplitudes of the averaged evoked responses were measured by computer. Evoked potentials influenced by bodily movement, as observed in the EEG, were discarded from the data.

\section{RESULTS}

The data consist of averages of 64 click-evoked potentials from three electrode locations: round window, cochlear nucleus, and auditory cortex. The data plotted in Figures 3 through 6 are averages obtained from 512 measurements from each electrode placement recorded on each of 4 cats. These figures show the average peak-topeak amplitudes of the auditory responses plotted as a function of auditory intensity for each of the three recording sessions: pretest control (cat nonattentive, receiving only auditory click stimuli), experimental (cat very attentive, receiving relevant auditory tones and irrelevant au- ditory clicks simultaneously), and posttest control (cat nonattentive, receiving only auditory click stimuli).

Figure 3 shows that the mean peak-to-peak amplitudes of auditory cortex click-evoked potentials were of a smaller amplitude when the cats were very attentive to the relevant auditory stimulus (S2) than when they were nonattentive. However, an analysis of variance (ANOVA) (Butler, Kamlet, \& Monty, 1969) indicated no significant differences between the recording sessions (pretest control, experimental, and posttest control) $[F(2,90)=1.57]$.

The mean peak-to-peak amplitudes of the cochlear nucleus as a function of recording session and increased auditory intensity appear in Figure 4 . The figure shows that when the attention of the cats was focused on the relevant auditory stimulus (S2), mean amplitudes of the cochlear nucleus click-evoked potentials changed very little when compared with the control recording sessions. An ANOVA indicated no significant differences between the pretest control, experimental, and posttest control sessions $(F<1)$.

Figure 5 shows the mean peak-to-peak amplitudes of the auditory nerve responses as a function of increased auditory intensity and attentive state. Again, the mean peak-to-peak auditory nerve responses did not change in amplitude when the cats were attentive to the relevant au- 


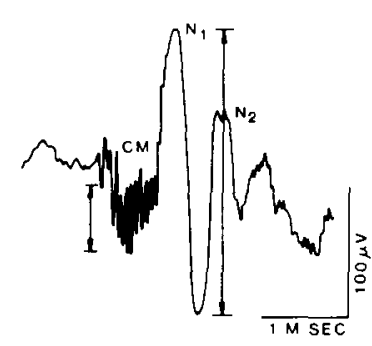

ROUND
WINDOW

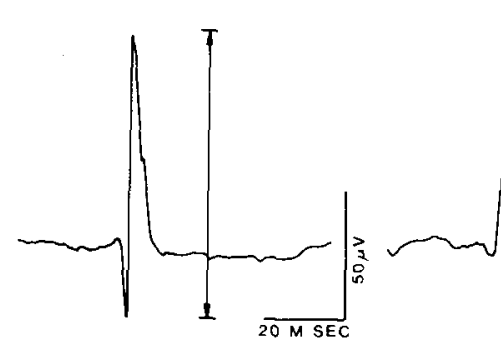

COCHLEAR

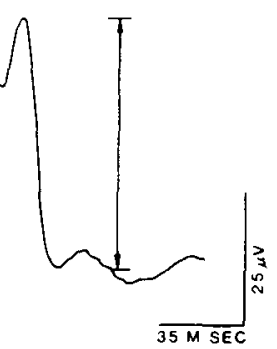

AUDITORY

Figure 2. Averaged click-evoked responses recorded from the cochlear nucleus and auditory cortex. The round window waveform shows cochlear microphonics (CM) and auditory nerve (N1-N2) responses to a single click. Peak-to-peak conventions used to quantify the evoked potentials are noted.

ditory stimulus (S2). An ANOVA indicated no significant differences between the pretest control, experimental, and posttest control recording sessions $(F<1)$.

The mean peak-to-peak amplitudes of the cochlear microphonic responses as a function of attentive state and increased auditory intensity appear in Figure 6, which shows that the mean amplitudes of the cochlear microphonic responses were not changed when the cats were attentive to the relevant auditory stimulus (S2). An ANOVA indicated no significant differences between the pretest control, experimental, and posttest control recording sessions $(F<1)$.

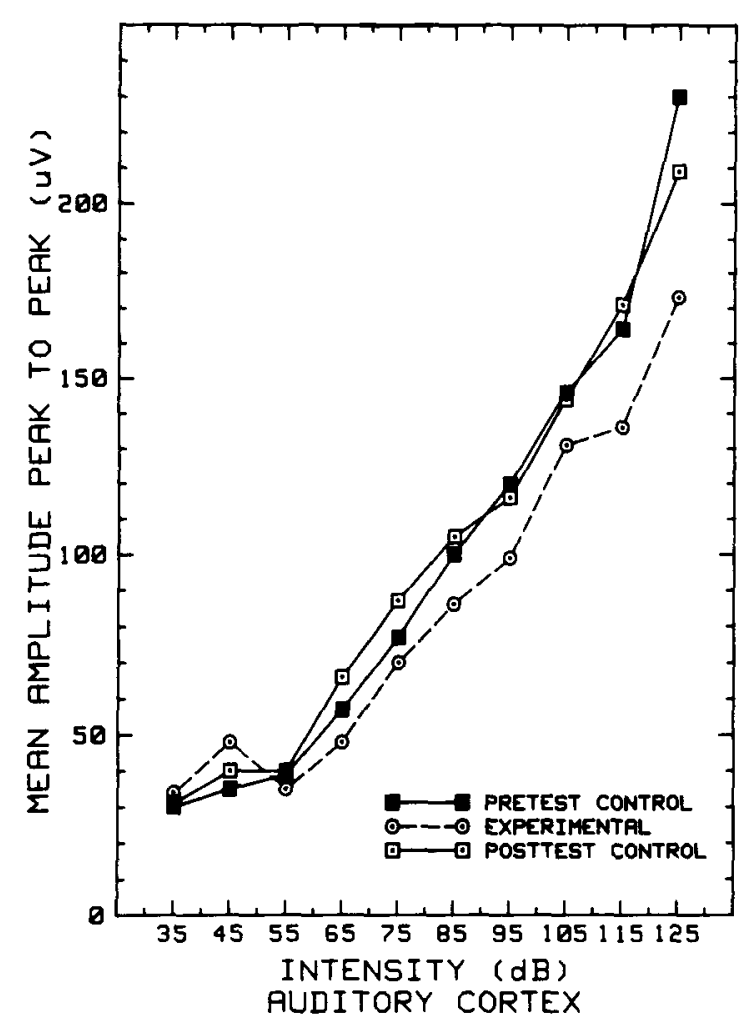

Figure 3. The mean peak-to-peak amplitude of auditory cortex evoked potentials (in microvolts) as a function of click intensity (decibels) and recording session.

\section{DISCUSSION}

One of the major objectives of this study was to determine whether the OCB performs an inhibitory gating function within the auditory modality during selective attention to auditory stimuli. The results of this experiment demonstrated that paying attention to a relevant auditory stimulus (S2) had no systematic effect on the irrelevant click-evoked responses within the S1-S2 interval recorded from the peripheral (cochlear microphonic, auditory nerve, or cochlear nucleus) or central (auditory cortex) auditory systems. For the parameters used in this study, it appears that irrelevant click-evoked potentials of increased intensity recorded from the auditory pathways are neither facilitated nor inhibited during changes in auditory attention. No evidence was obtained for peripheral gating by the OCB in the auditory system as a mechanism for early auditory selective attention.

By using the same experimental procedures and controls that were used in the cross-modality attention studies (Oatman, 1971, 1976, 1982), the present study examined the possibility that peripheral gating occurs within the auditory modality. If selective attention within the auditory modality initiated a peripheral gating effect, similar to the cross-modality effect, then the irrelevant click-evoked potentials would be suppressed in amplitude at the receptor level. The failure to demonstrate suppression of irrelevant click-evoked potentials during auditory attention, and thus the failure to demonstrate peripheral gating within the auditory modality, could not be due to the controls and procedures used in this experiment. The present experiment was designed to achieve control over the peripheral stimulus input to the auditory pathways, to eliminate the effects of the middle-ear muscles, and to control for the animal's own bodily movement by making all amplitude measures before the movements of the conditioned response. To obtain control over auditory-attention behavior in the cats, an S1-S2 response paradigm using food reinforcement was used. The method used to maintain the cats' attention was to delay the imperative-tone (S2) onset randomly between 1 and $6 \mathrm{sec}$. Instrumental conditioning using food reinforcement was the basic 


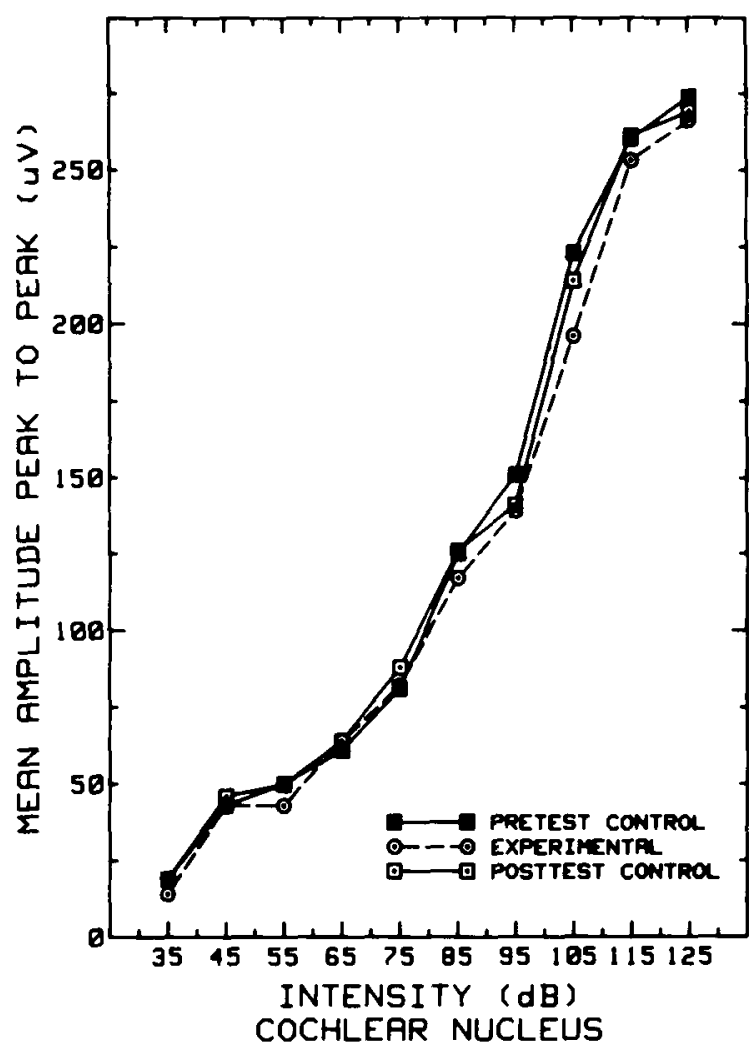

Figure 4. The mean peak-to-peak amplitude of cochlear nucleus evoked potentials (in microvolts) as a function of click intensity (decibels) and recording session.

method used to manipulate the significance of auditory stimuli to the auditory pathway. This type of task was similar to the successive visual task previously used in the cross-modality attention studies (Oatman 1971, 1976), which has been effective in altering the attentive states of the animals. The operational definition that the animals had attended to the relevant auditory tone (S2) was the behavioral response of pressing the response key. It might be argued that the lack of effect observed in the present experiment was due to the failure to command the animals' attention. This seems unlikely since the animals' behavioral responses in the present experiment confirmed that the animals were focusing their attention upon the relevant auditory stimulus (S2) to maintain the criterion level of performance. It should be noted that the present experiment used well-trained animals that were performing at learning asymptote.

Since the data were collected in three different recording sessions (pretest control, experimental, posttest control), there was a possibility that changes in the general arousal state between recording sessions could have affected the auditory evoked potentials (Karlin, 1970). A significant feature of the results reported here is that the amplitudes of the irrelevant click-evoked potentials did not change in the attention condition, whereas previous studies, notably those by Näätänen (1967) and Kitzes, Farley, and Starr (1978), using a similar paradigm with irrelevant tones presented within the S1-S2 interval or the conditioned stimulus-unconditioned stimulus interval, reported an enhancement in the evoked-potential amplitudes during attention conditions. If the warning stimulus (S1) triggered a heightened nonspecific arousal in preparation for the relevant stimulus (S2), as described in Näätänen's experiment, the evoked potentials to irrelevant stimuli within the S1-S2 interval might have been expected to be significantly larger in amplitude than the irrelevant click-evoked potentials in the nonattention control groups, but instead they were not significantly different. Although it is natural to assume that some form of increased arousal is likely to result between the nonperforming and the performing conditions, there is a lack of convergent evidence that such a manipulation did indeed create a change in state of arousal or alertness. The negative results in the present experiment suggest that differential arousal or alertness levels did not occur and that a state of heightened alertness was continuously maintained between the attention and nonattention recording sessions. This suggestion is supported somewhat by an analysis of the EEG activity recorded from the auditory cortex, which indicated no significant shifts in alpha activity between the attention and the nonattention recording sessions.

Hillyard et al. (1973) presented evidence that the N1 component of the evoked potential is reliably enhanced

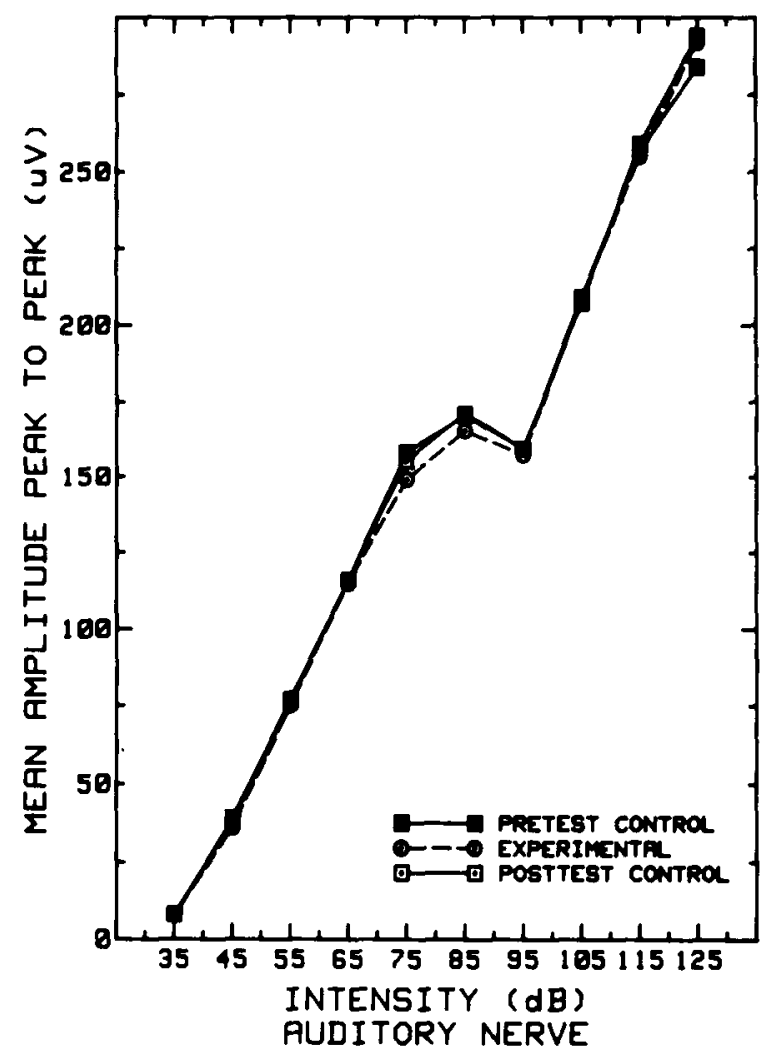

Figure 5. The mean peak-to-peak amplitude of auditory nerve responses (in microvolts) as a function of click intensity (decibels) and recording session. 


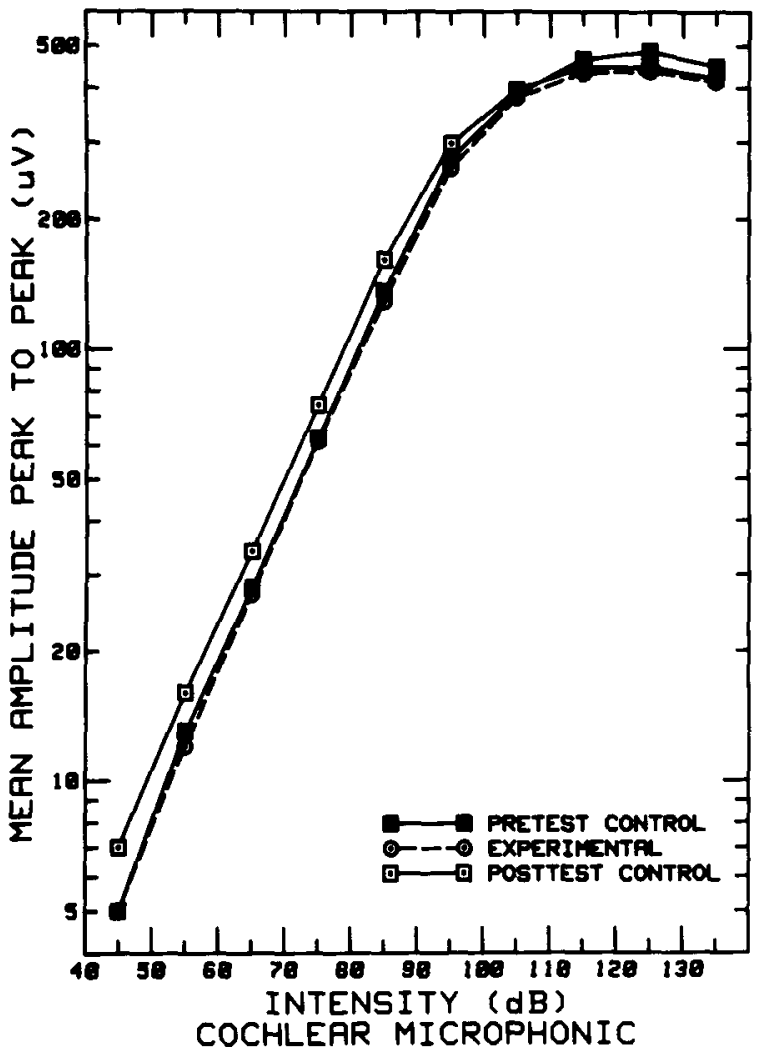

Figure 6. The mean peak-to-peak amplitude of cochlear microphonics (in microvolts) as a function of click intensity (decibels) and recording session.

over and above any changes due to arousal when attention is directed to the relevant stimuli, and that all the auditory stimuli in that channel-relevant and irrelevant alike-elicited ERPs with similarly enhanced N1 amplitudes (Hansen \& Hillyard, 1983). However, Hillyard, Picton, and Regan (1978) indicated that several stimulus conditions must be fulfilled before the N1 component of the evoked potential is differentiated between attended and nonattended stimuli and, furthermore, that the absence of attention effects upon the $\mathrm{N} 1$ component might be attributed to (1) very intense stimuli, (2) a slow rate of stimulus presentation, or (3) a lack of similar cues (i.e., one or more simple physical cue differences, such as pitch, spatial location, or intensity) between the relevant and irrelevant stimuli (Hillyard \& Picton, 1979).

It seems unlikely that the negative results observed in the present study can be attributed to one or more of the above stimulus conditions. First, since stimulus intensity has been shown to affect the size of the enhancement of the evoked potentials to the relevant auditory stimuli (Schwent, Hillyard, \& Galambos, 1976b), a wide range of irrelevant click intensities were presented in this study. However, the present experiment showed no evokedpotential enhancement at the cochlear nucleus or the auditory cortex to irrelevant clicks of either high or low intensity during attention to the relevant auditory stimulus (S2).
Second, a presentation rate of one per second was used in this study because significant changes in the irrelevant auditory evoked potentials were observed in the crossmodality studies (Oatman, 1971, 1976) using the same presentation rate. Insofar as the presentation rate can be thought of as increasing the processing load (Parasuraman, 1978), it might be argued that the failure to obtain enhancement of the irrelevant auditory evoked potentials was due to the stimulus presentation rate, and if shorter interstimulus intervals had been used, a change in evokedpotential amplitude would have been observed (Hansen \& Hillyard, 1984; Parasuraman, 1978, 1980; Schwent, Hillyard, \& Galambos, 1976a, 1976b). Although this possibility exists, it seems unlikely since the subjects were already heavily loaded with information processing by being required to attend to the relevant tones and to perform the S1-S2 response task.

Third, the lack of similar acoustic or physical attributes, such as pitch, spatial location, or intensity, between the relevant auditory tones and the irrelevant auditory clicks (Hillyard \& Picton, 1979; Woods, Hillyard, \& Hansen, 1984) may explain the negative results observed in the present study. An enhanced negativity to all stimuli, targets and nontargets alike, that shared easily discriminable attributes with the attended auditory stimuli have been reported in several studies (Hillyard \& Kutas, 1983; Hink, Hillyard, \& Benson, 1978; Okita, 1981). In contrast to these results, a major finding of the present study was that when attention was directed to the relevant stimuli, the amplitudes of irrelevant click-evoked potentials at the cochlear nucleus and auditory cortex did not change. This finding demonstrated that not all auditory stimuli delivered to the attended ear are enhanced in amplitude during attention to the relevant stimuli. It is conceivable that the auditory evoked potentials to the relevant tones could be enhanced in amplitude during auditory attention while the evoked potentials to click stimuli remain unchanged in amplitude because of their differences in acoustic or spectral characteristics. Thus, auditory attention could have been narrowly focused upon the spectral cues of the relevant tones, so that the irrelevant click stimuli with quite different spectral characteristics fell outside the "spotlight" of attention. This suggestion is supported by Woods et al. (1984), who found that focused attention to speech sounds in the attended ear did not produce significant changes in N1 amplitude to pure tones in the same ear when compared with tones in the unattended ear.

Although the present experiment focused on the irrelevant auditory evoked potentials within the S1-S2 inter$\mathrm{val}$, an assessment of the auditory evoked potentials to the warning tone (S1) and the relevant tone (S2) might have revealed an enhancement in amplitude during attentive behavior. A clearer result would have been obtained had we been able to simultaneously record the auditory evoked potentials to the relevant auditory tone stimuli as well as those to the irrelevant auditory click stimuli. It seems likely that the auditory evoked potentials to the relevant tone (S2) would be enhanced in amplitude during be- 
havioral response acquisition, since there have been many reports of the enhancement of single- and multiple-unit responses to a relevant positive auditory conditioned stimulus during classical conditioning (Diamond \& Weinberger, 1984; Ryugo \& Weinberger, 1978; Weinberger et al., 1984), avoidance conditioning (Gabriel, Miller, \& Saltwick, 1976; Gabriel, Orona, Foster, \& Lambert, 1982; Gabriel, Saltwick, \& Miller, 1975), and instrumental conditioning (Benson \& Hienz, 1978; Disterhoft \& Olds, 1972; Goldstein et al., 1982). However, the present study did not attempt to examine the effects of instrumental conditioning procedures upon neural activity within the auditory pathways during the acquisition of a behavioral conditioned response. All of the data were collected when the cats were well trained and performing at the criterion level. Therefore, these experiments were unable to provide insight into those neural processes that operate only during the initial acquisition of the behavioral response.

The present experiment demonstrated a clear dissociation between the amplitudes of the background irrelevant click-evoked potentials and behavioral performance. The dissociation may in part reflect the stage of learning of the S1-S2 response task. For example, during the animals' early stage of learning of the behavioral response, Weinberger and Diamond (1987) observed increases in both "spontaneous" or ongoing background neural activity and relevant tone-evoked neural activity within the auditory medial geniculate body and cortex. However, following this initial association between the conditioned stimulus and unconditioned stimulus, background activity did not change, while additional changes in evoked activity $\alpha$ curred. Changes in the background activity of cortical neurons occurred only during the initial acquisition stage of learning (Diamond \& Weinberger, 1984; Disterhoft \& Olds, 1972; Disterhoft \& Stuart, 1976; Weinberger \& Diamond, 1987), whereas background activity of cortical neurons did not change during the performance of overlearned responses (Benson \& Hienz, 1978; Benson, Hienz, \& Goldstein, 1981; Goldstein et al., 1982). Disterhoft and Olds (1972) described the changes in background spike rates in the posterior cortex and posterior thalamus as declining during the first $\mathbf{4 0}$ trials of conditioning, which was the period during which behavioral response conditioning occurred. At the end of this period, background rates in both the thalamus and cortex reached a reduced rate and remained constant. Because the present experiment used well-trained animals that were performing at learning asymptote, the observed dissociation between the background irrelevant click-evoked potentials within the S1-S2 interval and behavioral performance is in accord with previous studies (Benson \& Hienz, 1978; Benson et al., 1981; Goldstein et al., 1982) that reported no changes in background auditory cortical activity during the performance of overlearned responses.

In summary, for the parameters used in this experiment, the results show that when the cats were attentive to the relevant auditory stimulus (S2), no inhibition or enhancement of irrelevant auditory information took place. The evoked-potential responses to the irrelevant auditory stimuli within the S1-S2 interval had approximately the same amplitude during attention to the relevant auditory stimulus (S2) as during relaxed wakefulness preceding and following the presentation of the relevant tones. This study has shown that not all auditory stimuli delivered to the attended ear are enhanced in amplitude during attention to the relevant stimuli. These negative results cannot be accounted for simply by lack of controls of the auditory stimuli, the changes in arousal, or the intensity of the stimuli. However, the possibility exists that a slow rate of stimulus presentation might have produced negative results. In addition, the animals' attention could have been narrowly focused upon the frequency cues specific to the relevant tones without modulating the irrelevant clickevoked potentials with very different spectral characteristics.

The lack of auditory attention effects on irrelevant clickevoked potentials in the present study may, in part, reflect the stage of leaming of the S1-S2 response task. It would be expected that as an experimentally naive animal learned the $\mathrm{S} 1-\mathrm{S} 2$ response task, an increase in both background and relevant tone-evoked neural activity would occur. However, with extensive training on the $\mathbf{S} 1-\mathrm{S} 2$ response task, as in the present experiment, behavioral performance would be maintained while the background activity declined and remained constant. A clear dissociation was demonstrated between the amplitudes of the background irrelevant click-evoked potentials and behavioral performance. This dissociation could be attributed to the learning of automatic behavioral responses that do not require as much attention (Hillyard, 1974).

Although the results of the present study call into some question the generality of the concept of a precortical gating mechanism subserving the "stimulus set" mode of attention, the present data do not exclude precortical gating of auditory information during initial behavioral response acquisition. Although our previous studies (Oatman, 1971, 1976) demonstrated a cross-modality gating effect during selective attention, apparently it is not necessary that a similar gating function occur in every situation demanding selective attention (Hackley \& Graham, 1984). This view is consistent with the suggestion of Näätänen and Michie (1979) that there may be several forms of attention and that only certain forms of attention require a peripheral gating mechanism.

\section{REFERENCES}

Benson, D. A., HIenz, R. D. (1978). Single-unit activity in the auditory cortex of monkeys selectively attending left vs. right ear stimuli. Brain Research, 159, 307-320.

Benson, D. A., Hienz, R. D., Goldstein, M. H., JR. (1981). Singleunit activity in the auditory cortex of monkeys actively localizing sound sources: Spatial tuning and behavioral dependency. Brain Research, 219, 249-267.

BIRT, D., \& OLDS, M. (1981). Associative response changes in lateral midbrain tegmennum and medial geniculate during differential appetitive conditioning. Journal of Neurophysiology, 46, 1039-1055.

BIRT, D., OLDs, M. E. (1982). Auditory response enhancement dur- 
ing differential conditioning in behaving rats. In C. D. Woody (Ed.), Conditioning: Representation of involved neural function (pp. 483503). New York: Plenum.

Broadbent, D. E. (1958). Perception and communication. London: Pergamon Press.

Bũno, W., Velluti, R., Handler, P., Garcia-Austt, E. (1966). Neural control of the cochlear input in the wakeful free guinea pig. Physiology \& Behavior, 1, 23-35.

Butler, D. H., Kamlet, A. S., \& Monty, R. A. (1969). A multipurpose analysis of variance FORTRAN IV computer program. Psychonomic Monograph Supplements, 2(16, Whole No. 32).

Desmedt, J. E., \& Robertson, D. (1977). Differential enhancement of early and late components of the cerebral somatosensory evoked potentials during force-paced cognitive tasks in man. Journal of Physiology, 271, 761-782.

Deutsch, J. A., \& Deutsch, D. (1963). Attention: Some theoretical considerations. Psychological Review, 70, 80-90.

Diamond, D. M., \& Weinberger, N. M. (1984). Physiological plasticity of single neurons in auditory cortex of the cat during acquisition of the pupillary conditioned response: II. Secondary field (AII). Behavioral Neuroscience, 98, 189-210.

DisTERHoFT, J. F., OLDS, J. (1972). Differential development of conditioned unit changes in thalamus and cortex of rat. Journal of Neurophysiology, 35, 665-679.

DisterhoFt, J. F., \& STUART, D. K. (1976). Trial sequence of changed unit activity in auditory system of alert rat during conditioned response acquisition and extinction. Joumal of Neurophysiology, 39, 266-281.

Eıson, R. G. (1984). Selective attention effects on retinal and forebrain responses in humans: A replication and extension. Bulletin of the Psychonomic Society, 22, 341-344.

Eason, R. G., OAkley, M., \& Flowers, L. (1983). Central neural influences on the human retina during selective attention. Physiological Psychology, 11, 18-28.

Gabriel, M., Miller, J. D., \& Saltwick, S. E. (1976). Multipleunit activity of the rabbit medial geniculate nucleus in conditioning, extinction, and reversal. Physiological Psychology, 4, 124-134.

Gabriel, M., Orona, E., Foster, K., \& Lambert, R. W. (1982). Mechanism and generality of stimulus significance coding in a mammalian model system. In C. D. Woody (Ed.), Conditioning: Representation of involved neural function (pp. 535-565). New York: Plenum.

Gabriel, M., Saltwick, S. E., \& Miller, J. D. (1975). Conditioning and reversal of short-latency multiple-unit responses in the rabbit medial geniculate nucleus. Science, 189, 1108-1109.

Goldstein, M. H., Benson, D. A., \&IEnZ, R. D. (1982). Studies of auditory cortex in behaviorally trained monkeys. In C. D. Woody (Ed.), Conditioning: Representation of involved neural function (pp. 307-317). New York: Plenum.

Hackley, S. A., Graham, F. K. (1984). Early selective attention effects on cutaneous and acoustic blink reflexes. Physiological $P_{s y-}$ chology, 11, 235-242.

HANSEN, J. C., Hillyard, S. A. (1980). Endogenous brain potentials associated with selective auditory attention. Electroencephalography \& Clinical Neurophysiology, 49, 277-290.

HANSEN, J. C., \& HiLly ARD, S. A. (1983). Selective attention to multidimensional auditory stimuli. Joumal of Experimental Psychology: Human Perception \& Performance, 9, 1-19.

Hansen, J. C., Hillyard, S. A. (1984). Effects of stimulation rate and attribute cuing on event-related potentials during selective auditory attention. Psychophysiology, 21, 394-405.

Hernández-Peón, R. (1966). Physiological mechanisms in attention. In R. W. Russell (Ed.), Frontiers in physiological psychology (pp. 121144). New York: Academic Press.

Herníndez-Prón, R., Scherrer, H., \& Jouvet, M. (1956). Modification of electrical activity in cochlear nucleus during attention in unanesthetized cats. Science, 123, 331-332.

Hilly ARD, S. A. (1974). Methodological issues in CNV research. In R. F. Thompson \& M. M. Patterson (Eds.), Biolectric recording techniques (pp. 281-309). New York: Academic Press.

Hillyard, S. A., Hink, R. F., Schwent, V. L., Picton, T. W. (1973). Electrical signs of selective attention in the human brain. Science, 182, 177-180.
Hillyard, S. A., KuTAS, M. (1983). Electrophysiology of cognitive processing. Annual Review of Psychology, 34, 33-61.

Hilly ARD, S. A., \& MüNTE, T. F. (1984). Selective attention to color and location: An analysis with event-related brain potentials. Perception \& Psychophysics, 36, 185-198.

Hillyard, S. A., Picton, T. (1979). Event-related brain potentials and selective information processing in man. In J. Desmedt (Ed.), Progress in clinical neurophysiology: Vol. 6. Cognitive components in cerebral event-related potentials and selective attention (pp. 1-50). Basel, Switzerland: Karger.

Hillyard, S. A., Picton, T. W., Regan, D. M. (1978). Sensation, perception, and attention: Analysis using ERPs. In E. Callaway, P. Tueting, \& S. Koslow (Eds.), Event-related brain potentials in man (pp. 223-321). New York: Academic Press.

Hink, R. F., * Hillyard, S. A. (1976). Auditory evoked potentials during selective listening to dichotic speech messages. Perception \& Psychophysics, 20, 236-242.

Hink, R. F., Hilly ARd, S. A., \& Benson, P. J. (1978). Event-related brain potentials and selective attention to acoustic and phonetic cues. Biological Psychology, 6, 1-16.

KARLIN, L. (1970). Cognition, preparation, and sensory-evoked potentials. Psychological Bulletin, 73, 122-136.

Kitzes, L. M., FARLEY, G. R., \& STARR, A. (1978). Modulation of auditory cortex unit activity during the performance of a conditioned response. Experimental Neurology, 62, 678-697.

Lavine, R. A., Buchsbaum, M. S., \& Schechter, G. (1980). Human somatosensory evoked responses: Effects of attention and distraction on early components. Physiological Psychology, 8, 405-408.

LuKAs, J. H. (1980). Human auditory attention: The olivocochlear bundle may function as a peripheral filter. Psychophysiology, 17, 444-452.

LuKAs, J. H. (1981). The role of efferent inhibition in human auditory attention: An examination of the auditory brainstem potentials. International Journal of Neuroscience, 12, 137-145.

Mangun, G. R., Hansen, J. C., \& Hillyard, S. A. (1986). Electroretinogram reveals no evidence for centrifugal modulation of retinal inputs during selective attention in man. Psychophysiology, 23, 156-165.

NÄ̈̈T̈̈NEN, R. (1967). Selective attention and evoked potentials. Annales Academiae Scientiarum Fennicae, 151, 1-226.

Nä̈T̈̈NEN, R. (1982). Processing negativity: An evoked-potential reflection of selective attention. Psychological Bulletin, 92, 605-640.

NÄÄTÄNEN, R., MICHIE, P. T. (1979). Early selective-attention effects on the evoked potential: A critical review and reinterpretation. Biological Psychology, 8, 81-136.

Norman, D. A. (1968). Toward a theory of memory and attention. Psychological Review, 75, 522-536.

OAtman, L. C. (1971). Role of visual attention on auditory evoked potentials in unanesthetized cats. Experimental Neurology, 32, 341-356.

OAtman, L. C. (1976). Effects of visual attention on the intensity of auditory evoked potentials. Experimental Neurology, 51, 41-53.

OAtman, L. C. (1982). Spectral analysis of cortical EEG activity during visual attention. Physiological Psychology, 10, 336-342.

OAtman, L. C., A ANDerson, B. W. (1977). Effects of visual attention on tone burst evoked auditory potentials. Experimental Neurol. ogy, 57, 200-211.

OKITA, T. (1981). Slow negative shifts of the human event-related potential associated with selective information processing. Biological Psychology, 12, 63-75.

Oleson, T. D., Ashe, J. H., \& Weinberger, N. M. (1975). Modification of auditory and somatosensory system activity during pupillary conditioning in the paralyzed cat. Joumal of Neurophysiology, 38, 1114-1139.

Parasuraman, R. (1978). Auditory potentials and divided attention. Psychophysiology, 15, 460-465.

Parasuraman, R. (1980). Effects of information processing demands on slow negative shift latencies and $\mathrm{N} 100$ amplitude in selective and divided attention. Biological Psychology, 11, 217-233.

Picton, T. W., Hillyard, S. A. (1974). Human auditory evoked potentials: II. Effects of attention. Electroencephalography \& Clinical Neurophysiology, 36, 191-200. 
Picton, T. W., Hillyard, S. A., Galambos, R., \& Schiff, M. (1971). Human auditory attention: A central or peripheral process? Science, 173, 351-353.

Picton, T. W., Stapells, D. R., Campbell, K. B. (1981). Auditory evoked potentials from the human cochlea and brainstem. Journal of Otolaryngology, 10(Suppl. 9), 1-41.

Rasmussen, G. L. (1960). Efferent fibers of the cochlear nerve and cochlear nucleus. In W. S. Fields \& B. R. Alford (Eds.), Neurological aspects of auditory and vestibular disorders (pp. 105-115). Springfield, IL: Thomas Press.

Ryugo, D. K., * Weinberger, N. M. (1978). Differential plasticity of morphologically distinct neuron populations in the medial geniculate body of the cat during classical conditioning. Behavioral Biol. ogy, 22, 275-301.

SChWENT, V. L., \& HiLlyARD, S. A. (1975). Evoked potential correlates of selective attention with multi-channel auditory inputs. Electroencephalography \& Clinical Neurophysiology, 38, 131-138.

Schwent, V. L., Hillyard, S. A., \& Galambos, R. (1976a). Selective attention and the auditory vertex potential: I. Effects of stimulus delivery rate. Electroencephalography \& Clinical Neurophysiology, 40, 604-614.

Schwent, V. L., Hillyard, S. A., \& Galambos, R. (1976b). Selective attention and the auditory vertex potential: II. Effects of stimulus intensity and masking noise. Electroencephalography \& Clinical Neurophysiology, 40, 615-622.

SChwent, V. L., SNyder, E., Hillyard, S. A. (1976). Auditory evoked potentials during multi-channel selective listening: Role of pitch and localization cues. Journal of Experimental Psychology: Human Perception \& Performance, 2, 313-325.

SIEGEL, J. (1968). A rapid procedure for locating deep electrode placements. Physiology \& Behavior, 3, 203-204.

SNIDER, R., \&IEMER, W. T. (1961). A stereotaxic atlas of the cat brain. Chicago: University of Chicago Press

TECCE, J. J. (1972). Contingent negative variation (CNV) and psychological processes in man. Psychological Bulletin, 77, 73-108.
Treisman, A. (1969). Strategies and models of selective attention. Psychological Review, 76, 282-299.

Velasco, M., Velasco, F. (1975). Differential effect of task relevance on early and late components of cortical and subcortical somatic evoked potentials in man. Electroencephalography \& Clinical Neurophysiology, 39, 353-364.

Velasco, M., Velasco, F., \& Olvera, A. (1980). Effect of task relevance and selective attention on components of cortical and subcortical evoked potentials in man. Electroencephalography \& Clinical Neurophysiology, 48, 377-386.

Walter, W. G., Cooper, R., Aldridge, V. J., McCallum, W. C., * WINTER, A. L. (1964). Contingent negative variation: An electric sign of sensorimotor association and expectancy in the human brain Nature, 203, 380-384.

Wastell, D. G., K KLEInman, D. (1980). Evoked potential correlates of visual selective attention. Acta Psychologica, 46, 129-140.

Weinberger, N. M., \& Diamond, D. M. (1987). Physiological plasticity in auditory cortex: Rapid induction by learning. Progress in Neurobiology, 29, 1-55.

Weingerger, N. M., Hopians, W., Diamond, D. M. (1984). Physio logical plasticity of single neurons in auditory cortex of the cat during acquisition of the pupillary conditioned response: I. Primary field (AI). Behavioral Neuroscience, 98, 171-188.

Woods, D. L., Hillyard, S. A., HANSEN, J. C. (1984). Event-related brain potentials reveal similar attentional mechanisms during selective listening and shadowing. Joumal of Experimental Psychology: Human Perception \& Performance, 10, 761-777.

Worden, F. G. (1966). Attention and auditory physiology. In E. Stellar \& J. M. Sprague (Eds.), Progress in physiological psychology (pp. 45-107). New York: Academic Press.

(Manuscript received March 21, 1988; revision accepted for publication July 1,1988 .) 